Original Article

\title{
MICROBIOLOGICAL STUDY OF ORAL FLORA IN DIABETIC PATIENTS WITH GINGIVITIS
}

\author{
SAMIRA HSAINE ${ }^{*}{ }^{*}$, FATIMA ZAHRAE FETHI ${ }^{2}$, REDA CHAROF ${ }^{3}$, KHADIJA OUNINE ${ }^{1}$
}

${ }^{1}$ Department of Biology, Health and Environment, Applied Microbiology Team, Faculty of Sciences, Ibn Tofail University, Kenitra, Morocco, ${ }^{2}$ Dental Office of the Center for Chronic Diseases, Sale, Morocco, ${ }^{3}$ Department of Medical Bacteriology, National Institute of Hygiene, Rabat, Morocco

Email: samira.hsaine@gmail.com

Received: 27 Mar 2018 Revised and Accepted: 08 May 2018

\section{ABSTRACT}

Objective: Given the importance of the association between diabetes and periodontal disease, the main objective of the present study was to compare the microbial diversity responsible for gingivitis in patients with and without type 2 diabetes.

Methods: Samples were collected from the oral cavity of 134 patients with gingivitis and categorised into 3 groups (68 non-diabetic patients and 66 diabetic patients; 33 with controlled diabetes and 33 with poorly controlled diabetes). Sample culture was carried out on selective culture media. The identification of isolated strains involved a series of biochemical tests including miniature galleries (API 20E and 20 Strep), the traditional biochemical gallery (tubes) and automated bacterial identification (BD Phoenix ${ }^{\mathrm{TM}}$ ).

Results: Identification by biochemical methods made it possible to differentiate 14 bacterial species and one yeast. There was greater bacterial diversity in diabetic patients as compared to non-diabetic patients. Periodontal pathogens were isolated from both diabetic and non-diabetic populations; however, certain microbes such as Streptococcus acidominimus, Enterobacter cloacae, Klebsiella oxytoca, and Pseudomonas aeruginosa were present only in diabetics, with a much higher percentage in those with poorly controlled diabetes.

Conclusion: Poorly controlled diabetes causes metabolic dysregulation that can increase the severity of periodontal disease.

Keywords: Diabetes, Periodontal disease, Glycemic balance, Microbial diversity

(C) 2018 The Authors. Published by Innovare Academic Sciences Pvt Ltd. This is an open access article under the CC BY license (http://creativecommons.org/licenses/by/4.0/) DOI: http://dx.doi.org/10.22159/ijpps.2018v10i6.26295

\section{INTRODUCTION}

Oral diseases in diabetic patients have accelerated progression when the control of blood glucose is inadequate [1]. Advanced hyperglycemia may cause impairment of salivary gland function, the proliferation of pathogenic microorganisms, and progression of gum disease [2-4].

The prevalence of periodontal disease in diabetics is highly variable. It has been shown that $100 \%$ of diabetic patients had periodontal disease compared with $50 \%$ of control individuals $[4,5]$.

It is well documented that diabetics are more likely to develop periodontal infections than individuals without diabetes [6, 7]; with a reported prevalence of $9.8 \%$ in type 1 diabetics compared with $1.6 \%$ in non-diabetic patients. In patients with type 2 diabetes, which is the most common form of diabetes $195 \%$ of the diabetic population [8]), the risk of periodontal disease is three times higher than in the general population [9].

It is not well known that periodontal disease is considered the sixth greatest complication of diabetes, especially when the disease is not appropriately controlled $[10,11]$, and determines changes in the bacterial population and production of inflammatory mediators, which reduces the effectiveness of the host response [12]. Controlled diabetes does not pose a major risk of periodontitis, and the results of initial and surgical periodontal therapy are better in these patients. In addition, periodontal therapy can reduce insulin demand in diabetics [13].

As a result, periodontal diseases and diabetes have a bi-directional link [14]. The treatment of diabetes therefore also involves the treatment of periodontal disease and the maintenance of rigorous oral hygiene [15]. Reciprocally, healthy periodontal status and good plaque control will, in turn, improve glycemic control, resulting in a significant reduction in glycated hemoglobin (HbA1c) [16].

Given the importance of the association between diabetes and periodontal disease, the main goal of the present study was to investigate how diabetes affects host-bacterial interactions by focusing on the microbial diversity responsible for gingivitis in patients with and without type 2 diabetes.

\section{MATERIALS AND METHODS}

The present study was carried out at the Dental Office of the Centre for Chronic Diseases, Sale, Morocco. Before taking the samples, all participants signed their consent.

\section{Target population}

-Group I: 68 non-diabetic subjects.

-Group II: 33 diabetic subjects with controlled diabetes.

-Group III: 33 diabetic subjects with poorly controlled diabetes.

\section{Sample collection}

Swab specimens were taken from the oral cavity of diabetic and nondiabetic patients with gingivitis and streaked onto culture media. Subjects who used antiseptic mouthwashes during the week prior to collection, as well as those who took antibiotics in the previous month, were excluded from the study. Individuals of both genders were included, who did not suffer from systemic diseases other than type 2 diabetes, were non-smokers, and did not carry dentures or orthodontic appliances. Pregnant or breastfeeding women were also excluded from the present study.

\section{Seeding and isolation}

Sample seeding was carried out on cystine lactose electrolyte deficient (CLED) or bromocresol purple (BCP) medium and incubated at $37^{\circ} \mathrm{C}$ for $24 \mathrm{~h}$. Purification of bacterial colonies was performed by successive subcultures on the same medium or another selective medium.

Pseudomonas aeruginosa strains were isolated on nutrient agar supplemented with cetrimide, Escherichia coli and Klebsiella strains 
were isolated on methylene blue eosin (MBE) agar, and Streptococcus and Enterococcus strains were isolated on blood agar. All plates were incubated at $37^{\circ} \mathrm{C}$ in a $10 \% \mathrm{CO}_{2}$ atmosphere for $24 \mathrm{~h} \mathrm{[17].}$

\section{Identification of isolated pathogens}

Identification of strains was based on a series of preliminary tests (appearance of colonies, Gram stain), biochemical tests (catalase, oxidase, coagulase, and DNase), and identification by miniature galleries (API 20E and 20 Strep), the traditional biochemical gallery (tubes), and automated bacterial identification (BD Phoenix ${ }^{\mathrm{TM}}$ ) $[18,19]$.

\section{Statistical analysis}

The data were analyzed using SPSS (Statistical Package for Social Sciences) software version 21 . The Kolmogorov-Smirnov test was used to study the distribution of the quantitative variable, age, which is expressed as the median and quartile. Comparison of the qualitative variables among the three populations (gender, hygiene parameters, and microbial flora) was carried out by the Pearson khi2 test or Fisher's lowest difference test (LSD). The Mann Whitney test was used to compare variables with non-Gaussian distribution (age of patients). A value of $p<0.05$ is considered statistically significant.

\section{RESULTS}

\section{Distribution of the studied population}

Statistical analysis allowed us to divide our samples according to the demographic and hygiene parameters presented in table 1.

Table 1: Distribution of the diabetic and non-diabetic populations by demographic and hygiene parameters

\begin{tabular}{llll}
\hline Variables & Study population n=134 & Diabetic patients n = 66 & \\
\cline { 2 - 3 } & Non-diabetic patients $\mathbf{n = 6 8}$ & $50(33.50-59.25)$ & 0.168 \\
\hline Age $^{\mathrm{a}}$ & $55(39.75-60)$ & $48(68.6 \%)$ & 0.491 \\
Fender & & $18(60.0 \%)$ & 0.650 \\
Male & $44(31.4 \%)$ & & \\
Calculus & $24(40.0 \%)$ & $21(70.0 \%)$ & 0.827 \\
Absent & & $45(64.30 \%)$ & \\
Present & $18(30.0 \%)$ & & \\
Brushing & $50(35.7 \%)$ & $23(63.9 \%)$ & \\
No & $26(36.1 \%)$ & $43(67.2 \%)$ & \\
Yes & $42(32.8 \%)$ & & \\
\hline
\end{tabular}

aValues are expressed as the median and quartiles, bvalues are expressed as numbers and percentages. $p<0.05$ is considered statistically significant. The median age of the population was 52 (36-60) with extremes of 21 and 66 y old. The distribution by gender revealed a female predominance of $70 \%$ and a gender ratio of 0.42 . The oral examination revealed the presence of calculus in $70 \%$ of the study population. $63 \%$ of the entire population brushed their teeth daily.

\section{Identification of isolated pathogens}

15 strains were isolated, and their identification revealed 14 bacteria including 8 genres; Streptococcus, Enterococcus, Staphylococcus, Enterobacter, Escherichia, Klebsiella, Pseudomonas, and Lactobacillus, as well as one yeast Candida albicans (table 2).
Periodontal pathogens were present in both diabetic and nondiabetic populations. There was greater bacterial diversity in diabetic patients compared with non-diabetic subjects, with certain pathogens such as Streptococcus acidominimus, Enterobacter cloacae, Klebsiella oxytoca, and Pseudomonas aeruginosa only being present in diabetics.

Table 2: Distribution of pathogens isolated from the oral flora of diabetic and non-diabetic patients with gingivitis

\begin{tabular}{|c|c|c|c|}
\hline \multirow[t]{2}{*}{ Strain } & \multicolumn{2}{|l|}{ Study population $=134$} & \multirow[t]{2}{*}{$p$} \\
\hline & Non-diabetic patients $n=68$ & Diabetic patients $n=66$ & \\
\hline Streptococcus constellatus & $4(18.2 \%)$ & $9(81.8 \%)$ & 0.324 \\
\hline Streptococcus acidominimus & $0(0 \%)$ & $16(100 \%)$ & 0.002 \\
\hline Streptococcus oralis & $14(26.9 \%)$ & $19(73.1 \%)$ & 0.373 \\
\hline Enterococcus faecalis & $10(26.3 \%)$ & $14(73.7 \%)$ & 0.432 \\
\hline Streptococcus spp & $14(58.3 \%)$ & $5(41.7 \%)$ & 0.1 \\
\hline Streptococcus sanguinis & $10(50 \%)$ & $5(50 \%)$ & 0.301 \\
\hline Streptococcus mitis & $12(50 \%)$ & $6(50 \%)$ & 0.329 \\
\hline Streptococcus mutans & $2(100 \%)$ & $0(0 \%)$ & 0.113 \\
\hline Staphylococcus aureus & $6(30 \%)$ & $7(70 \%)$ & 1.000 \\
\hline Enterobacter cloacae & $0(0 \%)$ & $20(100 \%)$ & 0.001 \\
\hline Klebsiella oxytoca & $0(0 \%)$ & $14(100 \%)$ & 0.002 \\
\hline Escherichia coli & $2(12.5 \%)$ & $7(87.5 \%)$ & 0.259 \\
\hline Pseudomonas aeruginosa & $0(0 \%)$ & $7(100 \%)$ & 0.002 \\
\hline Lactobacillus acidophilus & $6(30 \%)$ & $7(70 \%)$ & 1.000 \\
\hline Candida albicans & $8(28.6 \%)$ & $10(71.4 \%)$ & 0.767 \\
\hline
\end{tabular}

Values are expressed as numbers and percentages. $p<0.05$ is considered statistically significant.

The distribution of the diabetic population according to glycemic balance revealed that $50 \%$ of the population presents with poorly controlled diabetes (fig. 1).

It is noteworthy that the percentage of ten microbial species identified in diabetic patients with poorly controlled diabetes is much higher than that in the group with controlled diabetes
(Streptococcus constellatus (48\%), Streptococcus acidominimus (63\%), Streptococcus oralis (43\%), Enterococcus faecalis (53\%), Staphylococcus aureus (60\%), Enterobacter cloacae (80\%), Klebsiella oxytoca (93\%), Escherichia coli (63\%), Pseudomonas aeruginosa $(100 \%)$, and Candida albicans (58\%). Moreover, these species are also present in very high numbers as compared with non-diabetic subjects. 


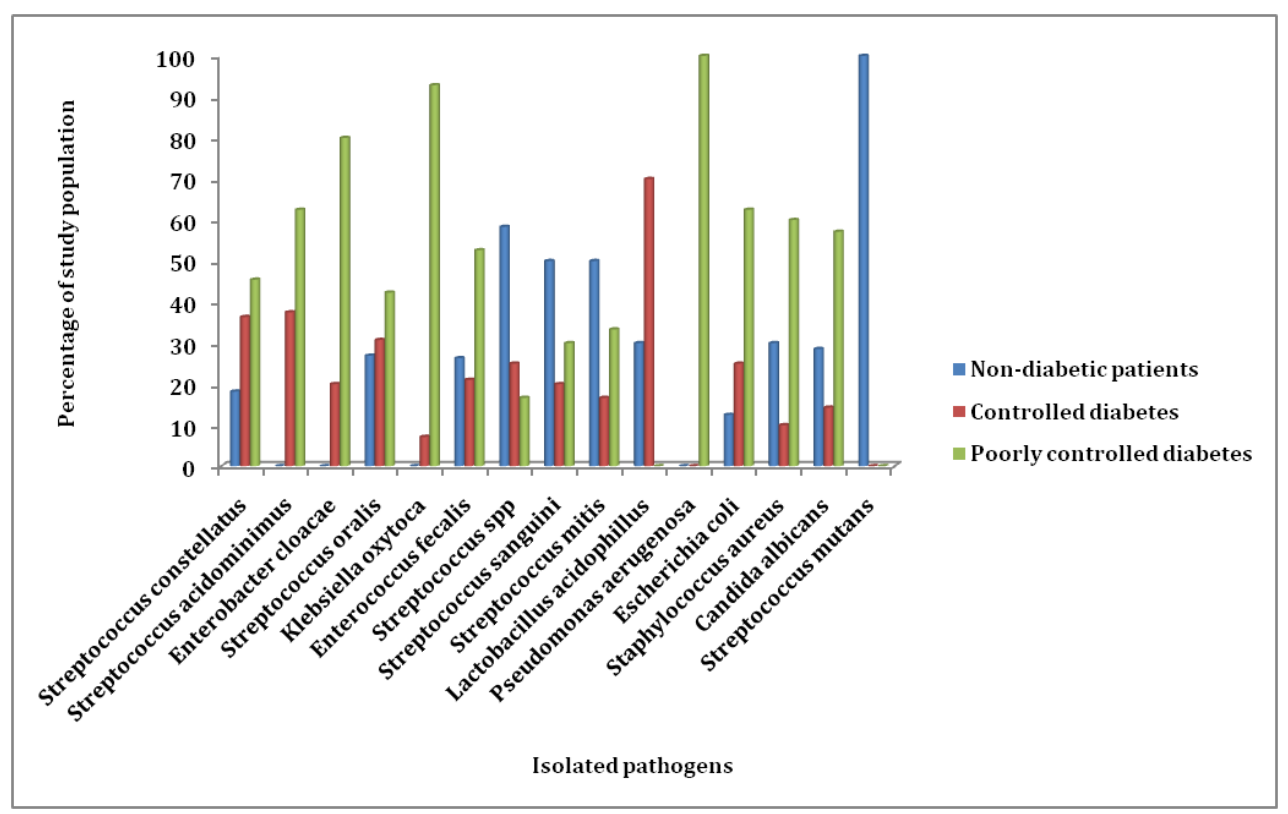

Fig. 1: Distribution of microbial species according to glycemic equilibrium within the study population

\section{DISCUSSION}

Diabetes can cause many serious systemic complications, with the classics including retinopathy, nephropathy, neuropathy, macrovascular, cerebrovascular, cardiovascular, and peripheral disorders [20], in addition to major alterations in the healing process. Increasing scientific evidence has also linked diabetes with periodontal disease $[21,22]$. The objective of the present study was to compare the microbial diversity responsible for gingivitis between diabetic and non-diabetic patients.

Based on clinical and radiological parameters, diabetic patients have shown an aggressive tendency towards bone loss as compared with healthy controls, suggesting that diabetes influences periodontal tissue destruction [23]. This is in accordance with studies that have demonstrated that a subject with type 2 diabetes is 2.8-3.4 times more likely to develop periodontal disease than a healthy subject $[23,24]$. Numerous epidemiological studies have shown that the incidence and prevalence of periodontitis, in addition to the severity of periodontal destruction, are higher in patients with type 1 and type 2 diabetes [2529]. Nelson et al., have shown that the prevalence of periodontal disease is approximately $60 \%$ higher in diabetic patients as compared with their non-diabetic counterparts [30].

In the present study, the bacteriological analysis showed a high concentration of microbial species considered as pathogenic (Streptococcus acidominimus, Enterobacter cloacae, Klebsiella oxytoca, and Pseudomonas aeruginosa) in diabetic subjects as compared with non-diabetic subjects, which is consistent with results reported by Sbordon et al., [31]. In patients with poorly controlled diabetes and periodontal problems, the percentage of the most virulent microbial species was higher than in subjects with controlled diabetes and non-diabetic subjects, which is in agreement with data reported by Seppaa and Ainamo [32]. Epidemiological studies have also shown that type 2 diabetes can be predictive of periodontal disease when the systemic conditions are poorly controlled $[33,34]$, in addition to responding poorer to surgical and non-surgical periodontal treatments $[35,36]$.

\section{CONCLUSION}

The results of the present study suggest that poorly controlled diabetes causes metabolic dysregulation that can increase the severity of periodontal disease. Numerous studies have shown that diabetes is associated with an increased risk of periodontal disease, which can be considered the sixth true complication of diabetes. Similarly, an oral infection can influence blood glucose control, insulin resistance, and the occurrence of complications associated with diabetes. Although more powerful studies are needed to complete the demonstration of the link between periodontal disease and glycemic control, we can already recommend integrating rigorous oral examination and necessary periodontal care (preventive and curative) into the management of diabetic patients.

\section{ACKNOWLEDGEMENT}

The authors would like to thank the Dental Office Team of the Center for Chronic Diseases, Sale, Morocco, for their providing facilities and their cordial support mostly Dr. FZ. Fethi.

\section{AUTHORS CONTRIBUTIONS}

The first author has carried out the research. Second third and fourth authors have provided study conception, the design of work, drafting of the manuscript and critical revision.

\section{CONFLICT OF INTERESTS}

\section{Declared none}

\section{REFERENCES}

1. Kidambi S, Patel SB. Diabetes mellitus: considerations for dentistry. J Am Dent Assoc 2008;139:8-18.

2. Negrato CA, Tarzia O. Buccal alterations in diabetes mellitus. Diabetol Metab Syndr 2010;15:2-3.

3. Uma Maheswari TN, Sri Neeraja P. Study of salivary $\mathrm{Ph}$ in patients with the prevalence of periodontitis with or without diabetes mellitus. Asian J Pharm Clin Res 2016;9:393-5.

4. Taylor GW, Borgnakke WS. Periodontal disease: Associations with diabetes, glycemic control and complications. Oral Dis 2008;14:191-203.

5. Carda C, Mosquera-Lloreda N, Salom L, Ferraris MEG, Peydró A. Structural and functional salivary disorders in type 2 diabetic patients. Med Oral Patol Oral Cir Bucal 2006;11:309-14.

6. Kumar M, Mishra L, Mohanty R, Nayak R. Diabetes and gum disease: the diabolic duo. Diabetes Metab Syndr 2014;8:255-8.

7. Shamit T, Tanvi T, Vishnu PV, Rajeev T, Reena T. Prevalence of periodontitis in diabetic and non-diabetic patients. Asian J Pharm Clin Res 2016;9:329-31.

8. Murti Andayani TRI, Mohamed Ibrahim MI, Asdie AH. Assessing the impact of complications on the direct medical costs of type 2 diabetes mellitus outpatients. Int J Curr Pharm Res 2010;2:32-5.

9. Vernillo AT. Dental considerations for the treatment of patients with diabetes mellitus. J Am Dent Assoc 2003;134:24-33. 
10. Chandini R, Radhika A, Gopinath P. Comparison of antifungal effects of commercially available herbal mouthwashes and chlorhexidine against Candida albicans. Asian J Pharm Clin Res 2016;9:214-6.

11. Löe H. Periodontal disease: the sixth complication of diabetes mellitus. Diabetes Carze 1993;16:329-34.

12. Kinane DF, Marshall GJ. Periodontal manifestations of systemic disease. Aust Dent J 2001;46:2-12.

13. Garofalo GS. Relationships between diabetes mellitus and periodontal disease: Current knowledge and therapeutic prospects. Clin Ter 2008;159:97-104.

14. Gurav AN. Periodontal therapy: an adjuvant for glycemic control. Diabetes Metab Syndr 2012;6:218-23.

15. Gurav AN. Management of diabolical diabetes mellitus and periodontitis nexus: are we doing enough? World J Diabetes 2016; 7:50-66.

16. Faria-Almeida R, Navarro A, Bascones A. Clinical and metabolic changes after conventional treatment of type 2 diabetic patients with chronic periodontitis. J Periodontol 2006;77:591-8.

17. Meunier O, Hernandez C, Piroird M, Heilig R, Steinbach D, Freyd A. Bacteriological sampling of surfaces: the importance of the enrichment stage and the choice of culture media. Ann Biol Clin 2005;63:481-6.

18. Holmes B, Willcox WR, Lapage SP. Identification of enterobacteriaceae by the API 20E system. J Clin Pathol 1978;31:22-30.

19. Etienne J, Reverdy ME, Gruer LD, Delorme V, Fleurette J. Evaluation of the API 20 STREP system for species identification of streptococci associated with infective endocarditis. Eur Heart J 1984;5:25-7.

20. Dhaliwal C, Erinmacpherson, Richardson J. Effectiveness of telephone-delivered interventions for increasing physical activity levels in persons with type 2 diabetes or hypertension: a systematic review. J Crit Rev 2015;2:6-11.

21. Mealy BL. Diabetes. Rose LF, Genco Rj, Mealy Bl, Cohen DW. 2000.

22. Mealy BL. Diabetes and periodontal diseases. Position Paper Am Acad Periodontol 1999;70:935-49.
23. Um YJ, Jung UW, Kim CS, Bak EJ, Cha JH, Yoo YJ, et al. The influence of diabetes mellitus on periodontal tissues: a pilot study. Periodontal Implant Sci 2010;40:49-55.

24. Shlossman M, Knowler WC, Pettitt DJ, Genco RJ. Type 2 diabetes mellitus and periodontal disease. J Am Dent Assoc 1999;121:532-6.

25. Sandberg G, Sundberg H, Fjellstrom C, Wikblad K. Type 2 diabetes and oral health: a comparison between diabetic and non-diabetic subjects. Diabetes Res Clin Prac 2000;1:27-34.

26. Soskolne W, Klinger A. The relationship between periodontal diseases and diabetes: an overview. Annals Periol 2001;1:91-8.

27. Genco R, Löe H. The role of systemic conditions and disorders in periodontal disease. J Periodontol 1993;2:98-116.

28. Emrich L, Shlossman M, Genco R. Periodontal disease in noninsulin dependent diabetes mellitus. J Periodontol 1991;2:123-31.

29. Taylor G, Burt B, Becker M, Genco R, Shlossman M, Knowler W, et al. Non-insulin dependent diabetes mellitus and alveolar bone loss progression over 2 y. J Periodontol 1998;1:76-83.

30. Nelson RG, Shlossman M, Budding LM, Pettitt DJ, Saad MF, Genco RJ, et al. Periodontal disease and NIDDM in Pima Indians. Diabetes Care 1990;13:836-40.

31. Sbordone L, Ramaglia L, Barone A, Ciaglia RN, Iacono VJ. Periodontal status and subgingival microbiota of insulindependent juvenile diabetics: A 3-year longitudinal study. J Periodontol 1998;69:120-8.

32. Seppaa B, Ainamo J. Darkfield microscopy of the subgingival microflora in insulin-dependent diabetics. J Clin Periodontol 1996;23:63-7.

33. Ryan ME, Carnu 0, Kamer A. The influence of diabetes on the periodontal tissues. J Am Dent Assoc 2003;134:34-40.

34. Guzman S, Karima M, Wang H, Van Dyke T. Association between interleukin-1 genotype and periodontal disease in a diabetic population. J Periodontol 2003;8:1183-90.

35. Tervonen T, Karjalainen K. Periodontal disease related to diabetic status: a pilot study of the response to periodontal therapy in type 1 diabetes. J Clin Periodontol 1997;7:505-10.

36. Christgau M, Paliztsch K, Schmalz G, Kreiner U, Frenzel S. Healing response to non-surgical periodontal therapy in patients with diabetes mellitus: Clinical, microbiological, and immunological results. J Clin Periodontol 1998;2:112-24. 